\title{
Descolamento de retina seroso em paraganglioma: relato de caso
}

\author{
Serous retinal detachment in paraganglioma: case report
}

\author{
Oscar Villas Boas ${ }^{1}$ \\ André Moura Bastos ${ }^{2}$ \\ Alexandre Campelo Ramiro ${ }^{3}$ \\ Roberto Alexandre Fonseca ${ }^{4}$
}

\section{RESUMO}

Os autores descrevem um caso de uma paciente gestante com hipertensão arterial resistente ao tratamento e descolamento seroso bilateral de retina. Confirmou-se, pelo exame anátomo-patológico, ser um paraganglioma.

Descritores: Feocromocitoma; Paraganglioma; Descolamento retiniano; Hipertensão ocular; Tomografia computadorizada por raios x; Adulto; Feminino; Relatos de casos [Tipo de publicação]

\section{INTRODUCÃO}

Feocromocitoma é uma neoplasia de células cromafins que tipicamente provoca sinais e sintomas de liberação episódica de catecolaminas ${ }^{(1-7)}$. O tumor constitui uma causa rara de hipertensão arterial sistêmica (HAS) (0,1\% dos casos) e tipicamente se estabelece o diagnóstico em adultos jovens. Em 10\% dos casos são extra-adrenais (paraganglioma), familiares (autossômicos dominantes) e associados à neoplasia endócrina múltipla (NEM) 2A, NEM-2B, von Hippel Lindau ou von Recklinghausen $^{(1-7)}$.

O feocromocitoma caracteriza-se classicamente pela tríade: palpitações, sudorese e cefaléia. A hipertensão refratária ao tratamento clínico também pode sugerir o diagnóstico, que é confirmado com a determinação das catecolaminas e seus metabólitos na urina de 24 h e anátomo-patológico da lesão. A determinação plasmática também pode ser obtida em caso de dúvidas ${ }^{(1-7)}$.

\section{RELATO DO CASO}

Paciente JNB, feminina, 19 anos, branca, 31 semanas de gestação encaminhada ao Serviço de Oftalmologia do Instituto Brasileiro de Oftalmologia e Prevenção à Cegueira (IBOPC) com história de "perda de visão" há 20 dias, associada à cefaléia holocraniana que respondia mal aos analgésicos comuns. Refere também palpitações e aumento intermitente dos níveis tensionais desde o segundo mês de gestação sendo introduzido metildopa sem melhora dos sintomas. Ao exame apresentava-se afebril, tensão arterial= 190x $140 \mathrm{mmHg}$, freqüência cardíaca=96, acuidade visual de conta dedos a 5 metros em ambos os olhos (AO), pressão intra-ocular de $10 \mathrm{mmHg}$ e descolamento exsudativo total de retina com estrela macular e edema de papila em AO (Figura 1 - olho direito).

Hemograma e sumário de urina sem alterações. Tomografia computadorizada de abdome evidenciou formação expansiva, sólida, de contornos regulares em retroperitôneo medindo 6,0 x 5,5 x 4,0 cm com área de necrose central (Figura 2). 
Catecolaminas urinárias vieram negativas. Optou-se pela exérese cirúrgica da lesão para estudo anátomo-patológico.

Após a cirurgia a paciente evoluiu com níveis tensionais normais e melhora progressiva da visão. Após 2 meses da cirurgia a retina estava toda aplicada com exsudatos duros em absorção e visão de 20/60 em AO.

A hipótese diagnóstica de feocromocitoma de origem extra-adrenal (paraganglioma) foi confirmada com estudo anátomo-patológico (Figura 3).

\section{DISCUSSÃO}

Feocromocitoma é uma neoplasia rara e por isso poucas vezes considerada como diagnóstico diferencial de HAS, sendo responsável por apenas $0,1 \%$ dos casos.

A paciente JNB, tinha de positivo ao exame uma hipertensão refratária ao tratamento clínico e descolamento seroso de retina.

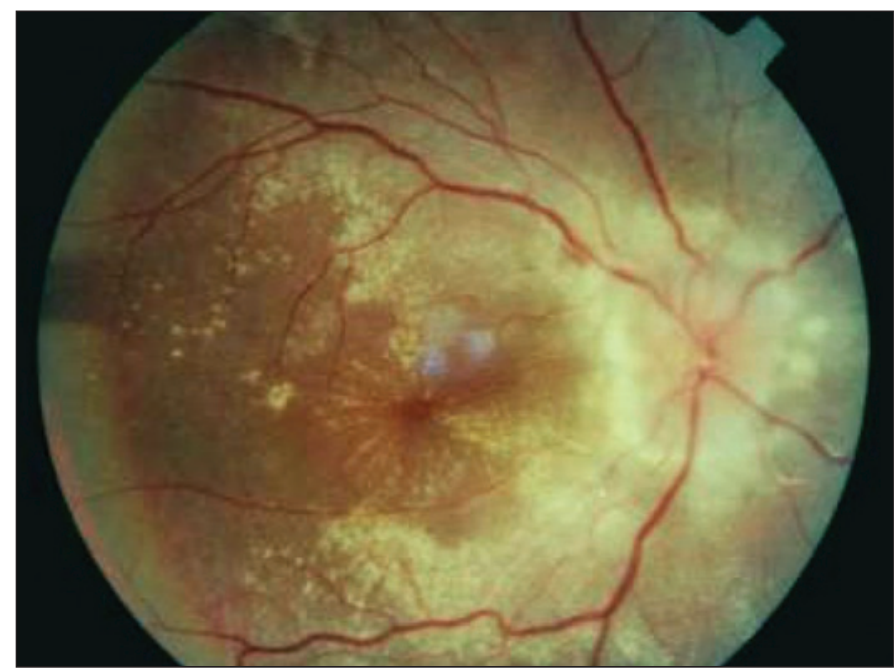

Figura 1 - Descolamento seroso de retina e edema de papila (olho direito)

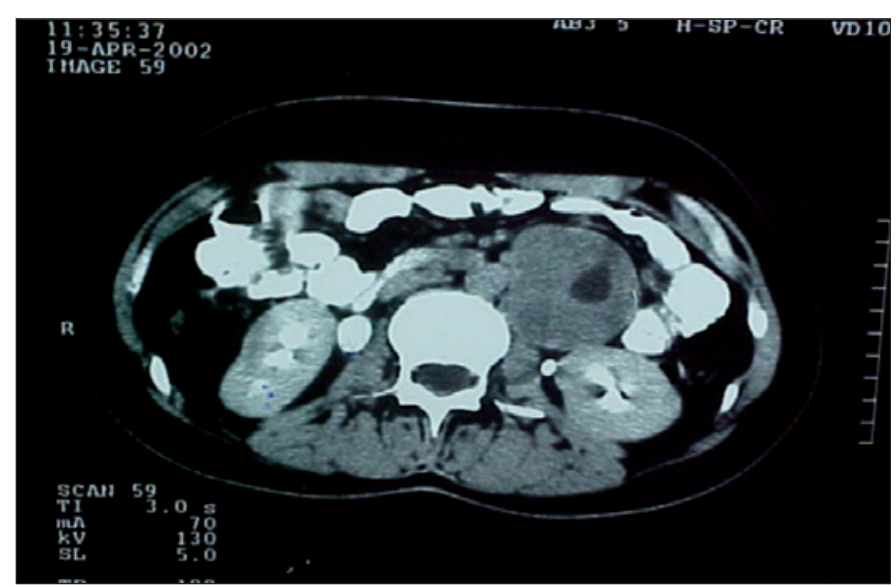

Figura 2 - Tomografia do abdome

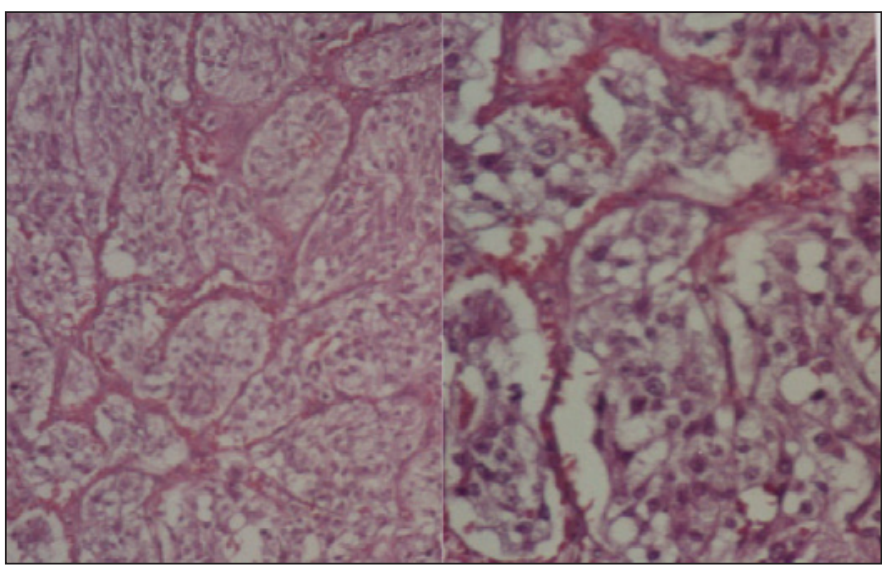

Figura 3 - Anátomo-patológico

As principais causas de descolamento seroso de retina foram levantadas como suspeita diagnóstica: corioretinopatia serosa central, Vogt-Koyanagi-Harada, oftalmia simpática, esclerite posterior, púrpura trobocitopênica trombótica, coagulação intravascular disseminada, eclâmpsia e hipertensão maligna $^{(8-10)}$. Por se tratar de uma mulher grávida o diagnóstico de eclâmpsia parecia óbvio, porém a paciente já apresentava hipertensão desde as primeiras semanas da gestação, fato que normalmente só ocorre em torno da vigésima semana na eclâmpsia, o exame de sumario de urina não demonstrava proteinúria e por fim o parto foi realizado imediatamente porém a paciente manteve-se com hipertensão refratária. A partir destes fatos suspeitamos de feocromocitoma e finalmente chegamos ao diagnóstico de uma doença rara que foi rapidamente elucidada com exérese cirúrgica.

$\mathrm{O}$ fato de se tratar de paraganglioma (feocromocitoma de origem extra-adrenal) associado ao descolamento seroso de retina podemos considerar esta entidade clínica bastante interessante e de valiosa contribuição didática a todos oftalmologistas e em especial aos retinólogos.

\section{ABSTRACT}

The authors describe a case of a pregnant patient with arterial hypertension that resists to the treatment and retinal bilateral serous detachment. It was confirmed to be a paraganglioma by anatomicopathological examination.

Keywords: Pheochromocytoma; Paraganglioma; Retinal detachment; Ocular hypertension; Tomography, x-ray computed; Adult; female; Case reports [Publication type]

\section{REFÊRENCIAS}

1. Cryer PE. Pheochromocytoma. West J Med. 1992;156(4):399-407.

2. Grossman E, Goldstein DS, Hoffman A, Keiser HR. Glucagon and clonidine 
testing in the diagnosis of pheochromocytoma. Hypertension. 1991;17(6 Pt 1):733-41.

3. Ross NS, Aron DC. Hormonal evaluation of the patient with incidentally discovered adrenal mass. N Engl J Med. 1991; 323(20):1401-5.

4. Héron E, Chatellier G, Billaud E, Foos E, Plouin PF. The urinary metanephrine-to-creatinine ratio for the diagnosis of pheochromocytoma. Ann Intern Med. 1009;125(4):300-3. Comment in: Ann Intern Med. 1996;125(4):331-2.
5. Werbel SS, Ober KP. Pheochromocytoma: Update on diagnosis, localization, and management. Med Clin North Am. 1995;79(1):131-53.

6. Scarpelli PT, Livi R, Caselli GM, Di Maria L, Teghini L, Montemurro V, et al. Accelerated (malignant) hypertension: a study of 121 cases between 1974 and 1996. J Nephrol. 1997;10(4):207-15.

7. Spaide RF, editor. Diseases of the retina and vitreous. New York: W.B. Saunders; c2000.

\section{Congresso da Associação Paranaense de Oftalmologia}

\section{Congresso Brasileiro de Glaucoma de Ângulo Fechado}

\section{Congresso Sul-Brasileiro da SOBLEC}

\section{3 e 14 de junho de 2008 Curitiba - PR}

Informações

Tels.: (41) 3039-8001/3232-4031 home page: www.congressoapo.com.br 